\title{
Spray propagation and mixture formation in an air guided direct injection gasoline engine
}

\author{
$\mathbf{P}$ Adomeit and $\mathbf{O}$ Lang \\ FEV Motorentechnik GmbH, Aachen, Germany
}

\section{S Pischinger}

Lehrstuhl für Verbrennungskraftmaschinen, RWTH Aachen, Germany

\section{Received 1 March 2000}

\begin{abstract}
Numerical analysis is used to gain information on the spray propagation and mixture formation in tumble guided gasoline direct injection (DI) engines. In order to achieve reliable predictions an atomization model for highpressure swirl injectors is described and verified by comparison to experimental data. The approach is capable of adequately predicting the most important effects, such as nozzle orifice diameter, cone angle or injection pressure on spray development. Furthermore, it is found that the pre-jet generated at the beginning of the injection strongly affects the overall spray development. The temporal development of the pre-jet is described empirically.

The in-cylinder computational fluid dynamics (CFD) analysis reveals that the tumble charge motion strongly affects spray propagation and mixture formation in the stratified operation mode, as it transports the fuel vapour cloud towards the spark plug. The CFD simulation improves understanding of the interaction between the flow field, spray propagation and evaporation and enables guidance of the optimization of the flow control and of the injection parameters for tumble guided gasoline DI engines.
\end{abstract}

Key words: spray propagation, mixture formation, tumble guided gasoline DI engines, swirl injectors, CFD

\section{Introduction}

One of the most promising approaches used to achieve a distinct reduction of fuel consumption for spark ignition (SI) engines is direct fuel injection. At part-load operation direct injection (DI) gasoline engines are able to run in a stratified charge mode, which combines the benefits of lean combustion with a nearly throttle free operation. This is the major step in overcoming the principal disadvantages of SI engines compared to diesel engines. At full-load operation the combustion system is switched to the homogeneous stoichiometric mode. At these conditions the in-cylinder charge is cooled by fuel spray evaporation. This increases both volumetric efficiency and reduces knock sensitivity, which results in a higher full-load performance.

In the stratified mode measures have to be taken to ensure that the fuel vapour cloud is transported towards the spark plug for ignition. For this purpose several types of combustion systems for DI gasoline engines are currently discussed:

(a) wall guided systems, where the fuel spray is deflected towards the spark plug by impingement on to the specially shaped piston;

(b) spray guided systems, in which the spray is directly injected towards the protruding spark plug;

(c) air guided systems, where a controlled tumble charge motion is used to deflect and transport the spray to the spark plug.

The present investigation focuses on air guided systems. This concept avoids fuel wall film formation and maintains a compact and central position of the piston bowl. Both are beneficial for the combustion process and reduce pollutant formation.

The stratified charge mode of a tumble guided DI gasoline engine requires an exact control of the charge 
motion to ensure that the fuel vapour cloud reaches the spark plug at the time of ignition. Charge motion is controlled by a continuously variable tumble system (CVTS), which is schematically shown in Fig. 1 . This system allows controlled blocking of the lower half of the split intake port in order to adjust the resulting tumble intensity to the desired value. Hence, the advantages of DI gasoline engines have to be paid for by a higher degree of system complexity. Here, computational fluid dynamics (CFD) simulations are very useful to gain process understanding and to investigate effects like the switching position of the tumble device and the injection parameters, i.e. the injector type and position, and injection timing, on engine behaviour.

StarCD is used to simulate in-cylinder flow and mixture formation at part-load conditions. To simulate the fuel spray propagation and evaporation StarCD's built-in Lagrangian droplet phase treatment is used to describe droplet motion and evaporation as well as droplet break-up and collision. These capabilities are extended by user routines for spray atomization modelling.

An exact description of the primary droplet characteristics and their subsequent break-up is essential for an accurate simulation of momentum, heat and mass transfer between the droplet and gas phases in the combustion chamber. Hence, the CFD modelling results have been carefully compared to experimental data obtained in a high-pressure-high-temperature injection chamber with optical access to the spray. After verification of the models, calculations of the incylinder flow field and mixture formation were performed.

\section{Numerical Approach}

StarCD is used here for the transient simulation of in-cylinder flow and mixture formation. The simu-

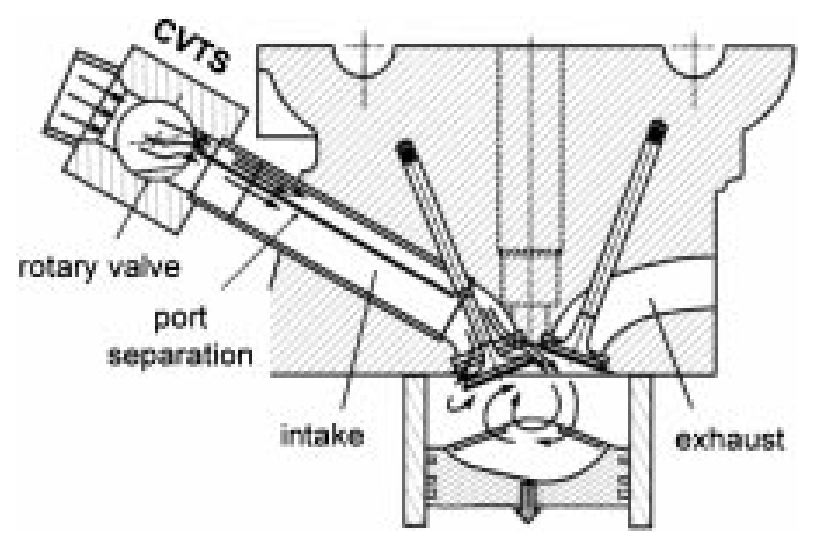

Fig. 1 Schematic of the CVTS intake port and the combustion chamber. lation covers the complete intake and compression stroke taking into account valve and piston motion. The unstructured hexahedral mesh consists of several subgrids, which are connected by arbitrary sliding interfaces. The overall size of the mesh is approximately 450000 hexahedral cells.

The mesh motion is generated by ProStar events and macro-routines for vertex generation and motion. In this way the cell layer addition or deactivation and the grid motion is controlled.

\subsection{Gas phase}

The numerical simulation of the in-cylinder flow and spray propagation is based on an Eulerian description of the gas phase and on a Lagrangian description of the droplet phase. The interaction between both phases is described by source terms for the momentum, heat and mass exchange. This methodology has become a standard for spray modelling and is also implemented in the CFD code Star CD.

The turbulent gas flow is described by a numerical solution of the complete ensemble-averaged equations of conservation of mass, momentum, energy and species mass fraction in an unstructered numerical mesh. Turbulence is modelled using a standard $k-\varepsilon$ model according to El Tahry [1].

\subsection{Droplet phase}

The droplets are considered as a disperse phase. Their trajectories are obtained from integration of the equation of motion. The momentum, heat and mass transfer between droplets and the gas phase are described by empirical correlations for the drag coefficient, the Nusselt number and the Sherwood number. In a turbulent gas stream an additional stochastic contribution to the relative motion between droplets and gas is induced by turbulent eddies. This effect, which causes droplet dispersion and enhances heat and mass transfer rates, is accounted for by a random walk concept by Gosman and Ioannides [2] implemented in the StarCD code.

\subsection{Injection, spray propagation and mixture formation}

The hydrodynamic processes in the high-pressure swirl injector (HPSI) and the spray atomization at the nozzle exit are very complex phenomena. At present only simplified approaches are available to describe the atomization process, which are based partially on physical but also on empirical considerations. Here, the atomization model of Han et al. [3] is used. Figure 2 sketches the basic idea of this model. It is assumed that the conical liquid sheet can be described as a conjunction of liquid blobs. They are 


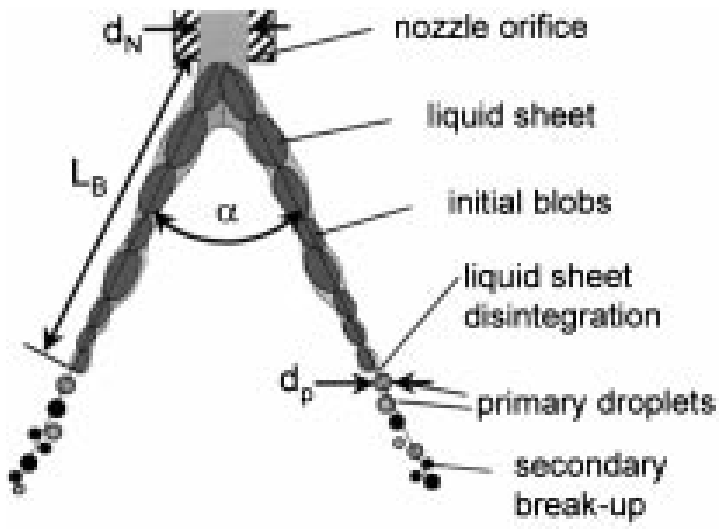

Fig. 2 Schematic of the atomization process for high-pressure swirl injectors.

characterized by a diameter that is equivalent to the liquid sheet thickness $h$. Their propagation is limited to the liquid sheet break-up length $L$. Having passed the sheet break-up length, the initial blobs undergo further disintegration.

The theoretical framework to obtain the initial blob size and velocity in dependence upon cone angle, nozzle diameter, fuel flowrate, pressure and properties is found in Han et al. [3] and will not be repeated here. The further disintegration-the secondary break-up-of the initial droplets is described by the well-known approach of Reitz and Diwakar [4], which is implemented in StarCD. This model distinguishes between two main mechanisms. The 'bag break-up' regime is characterized by large droplet deformations and occurs at moderate Weber numbers. In the 'stripping break-up' regime secondary droplets are stripped from the surface. This regime is typical for rather high Weber numbers.

Of great importance is the transient behaviour of the injector. As the needle is lifted, the flow inside the swirl injector develops and builds up angular momentum. During this phase of flow development a liquid jet is discharged at the nozzle orifice, frequently referred to as the 'pre-jet'. As the flow develops this jet transforms into a conical liquid sheet at the nozzle exit. Cousin et al. [5] investigated the transient flow development numerically and found that it requires approximately $0.11 \mathrm{~ms}$ to establish the full angular momentum of the swirl flow. This delay corresponds exactly with the time needed to develop a stable conical liquid sheet at the nozzle exit.

The pre-jet is accounted for empirically by assuming a temporal development of the spray angle $\alpha$, which differs from the cone angle during main injection. The duration of the pre-jet $t_{\text {pre }}$ was determined by measurements. The pre-jet significantly affects the spray propagation and evaporation. As the liquid core of the pre-jet has a similar diameter to the orifice, the primary droplets are significantly coarser then those resulting from a hollow cone liquid sheet. Due to the momentum entry of the prejet a secondary gas flow is induced which builds up a recirculation zone. This induced gas flow contracts the main conical spray.

\section{Results}

\subsection{Spray propagation and evaporation}

Several injectors and injection parameters have been investigated, which are listed in Table 1. The StarCD results of spray propagation and evaporation are directly compared to Schlieren spray images at discrete time increments after the start of injection. Figure 3 shows the spray development at an ambient pressure and temperature of $0.15 \mathrm{MPa}$ and $323 \mathrm{~K}$ with the injection conditions A of Table 1. Schlieren visualization detects both the light extinction by Mie scattering at the droplets and the diffraction by temperature and concentration gradients within the gas phase. Therefore, both droplets and vapour concentration are overlaid in the CFD results for better comparison.

Figure 3 shows a good quantitative agreement between CFD simulation and Schlieren visualization. The temporal delay of the swirl flow development during injection is clearly seen, which causes the injection to start with a straight pre-jet and to turn subsequently to a hollow cone spray. The pre-jet has

\begin{tabular}{|llllll|}
\hline $\begin{array}{l}\text { Parameter } \\
\text { set }\end{array}$ & $\begin{array}{l}\text { Nozzle } \\
\text { diameter } \\
(\mathbf{m m})\end{array}$ & $\begin{array}{l}\text { Cone } \\
\text { angle } \\
\mathbf{( d e g )}\end{array}$ & $\begin{array}{l}\text { Rail } \\
\text { pressure } \\
(\mathbf{M P a})\end{array}$ & $\begin{array}{l}\text { Injection } \\
\text { duration } \\
(\mathbf{m s})\end{array}$ & $\begin{array}{l}\text { Injected } \\
\text { volume } \\
\left(\mathbf{m m}^{\mathbf{3}} \mathbf{)}\right.\end{array}$ \\
\hline A & 0.62 & 60 & 8 & 1.5 & 13.97 \\
B & 1.0 & 60 & 8 & 1.5 & 15.11 \\
C & 1.0 & 60 & 10 & 1.5 & 16.94 \\
D & 1.0 & 75 & 8 & 1.5 & 15.98 \\
E & 0.62 & 75 & 8 & 0.83 & 8.03 \\
\hline
\end{tabular}

Table 1 Characteristics of the injection parameters investigated. 


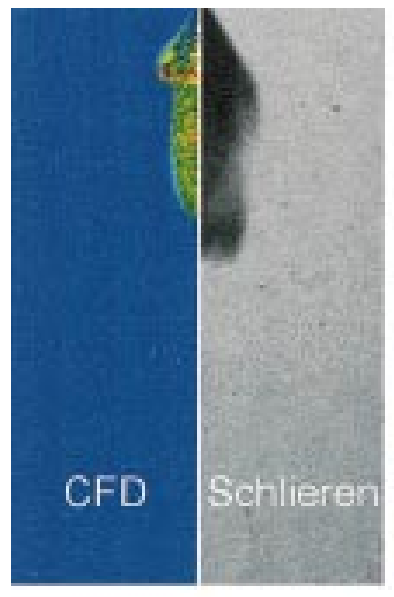

$\mathrm{t}=0.25 \mathrm{~ms}$

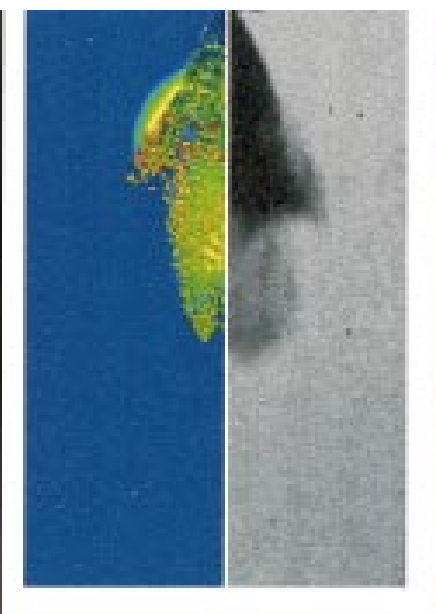

$0.45 \mathrm{~ms}$

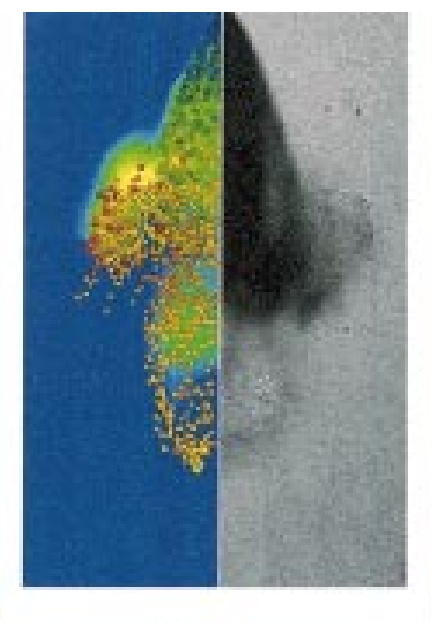

$0.85 \mathrm{~ms}$

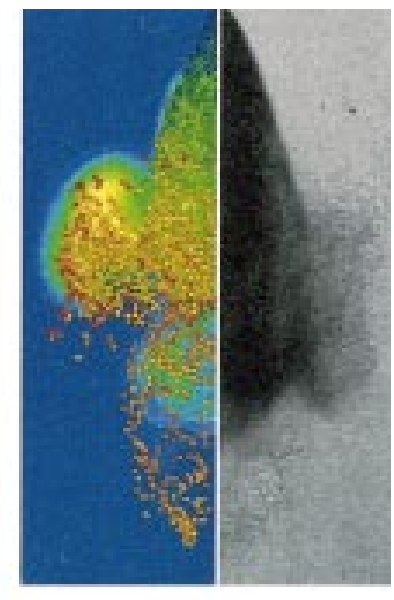

$1.25 \mathrm{~ms}$

Fig. 3 Temporal spray development: numerical simulation results compared to Schlieren visualization at $0.15 \mathrm{MPa}$ and $323 \mathrm{~K}$, injection parameter set $A$.

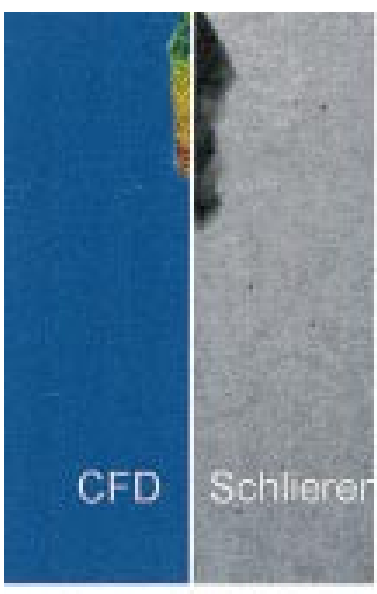

$\mathrm{t}=0.25 \mathrm{~ms}$

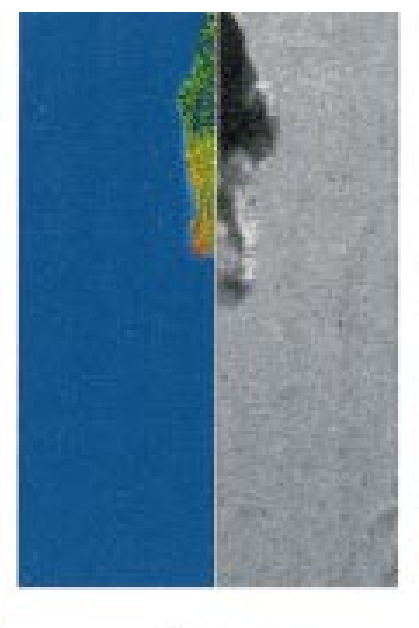

$0.45 \mathrm{~ms}$

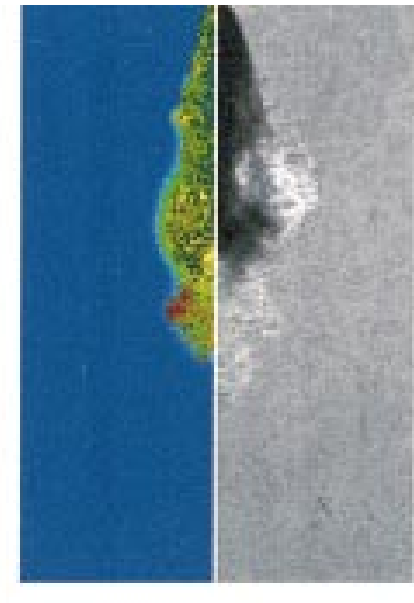

$0.85 \mathrm{~ms}$

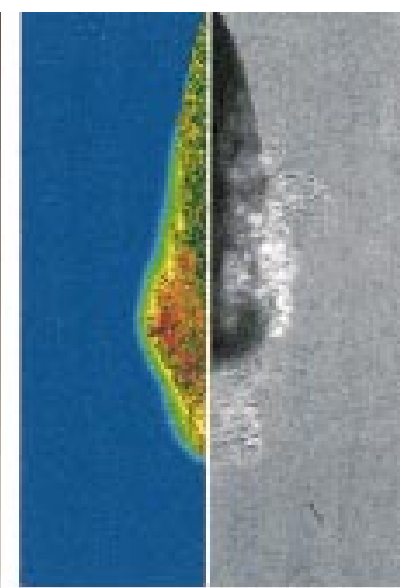

$1.25 \mathrm{~ms}$

Fig. 4 Temporal spray development: numerical simulation results compared to Schlieren visualization at $0.8 \mathrm{MPa}$ and $570 \mathrm{~K}$, injection parameter set $A$.
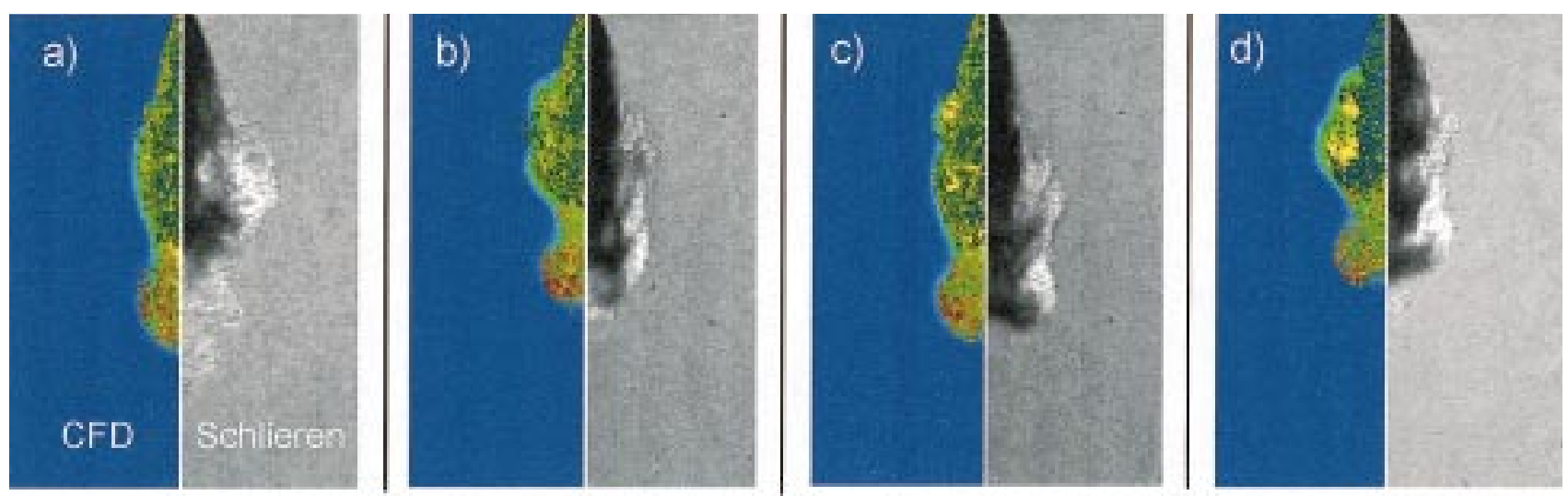

Fig. 5 Comparison of numerically predicted and visualized spray patterns $0.85 \mathrm{~ms}$ after BOI at $0.8 \mathrm{MPa}$ and $570 \mathrm{~K}$ : (a) injection parameter set $A,(b)$ injection parameter set $B,(c)$ injection parameter set $C,(d)$ injection parameter set $D$. 
a high velocity and precedes the conical main spray during the complete injection. As the gas density is comparatively small, the effect of the gas recirculation on the spray development is small and the conical spray gains full width.

Figure 4 shows the results obtained at an elevated chamber pressure of $0.8 \mathrm{MPa}$ and temperature $570 \mathrm{~K}$ with the same injection parameters A. Due to the higher gas density the main conical spray is strongly contracted. Additionally, the pre-jet is decelerated more strongly, so that it is increasingly overtaken by the main spray as seen at $t=1.25 \mathrm{~ms}$ after BOI.

Figure 5 gives an overview of the spray patterns at $t=0.85 \mathrm{~ms}$ for the various injection parameters given in Table 1. Injections were performed for chamber conditions $0.8 \mathrm{MPa}$ and $570 \mathrm{~K}$. In Fig. 5a (injection parameter A) and Fig. $5 \mathrm{~b}$ (injection parameter B) the effect of the nozzle diameter is compared. At a constant injection rate, the finer nozzle hole (Fig. 5a) generates a higher momentum and thus a larger spray penetration depth. Figures $5 b$ and $c$ show the effect of increasing the rail pressure from 8 to $10 \mathrm{MPa}$, which causes an increase of the spray penetration length. The spray width is not affected by the injection pressure.

The effect of the injector nozzle cone angle can be seen by comparing Fig. $5 d, \alpha=75^{\circ}$, with Fig. 5 b, $\alpha=60^{\circ}$. The larger cone angle causes both a shorter spray penetration and a slight increase in spray width. These effects are also predicted by the CFD calculation and agree quantitatively to the measurements.

Overall the comparison of CFD simulations to the Schlieren visualization in Fig. 5 shows that the modified atomization model utilized here is capable of predicting adequately the most important effects, such as nozzle orifice diameter, cone angle or injection pressure on spray development. A quantitative comparison of the spray droplet properties has been obtained by phase Doppler anemometry (PDA). PDA droplet analysis has been performed at ambient pressure and temperature, $0.1 \mathrm{MPa}$ and $298 \mathrm{~K}$ in a measurement plane $50 \mathrm{~mm}$ below the nozzle exit. In Fig. 6 the PDA results and the numerical predictions of the droplet size distribution are shown. The most frequent diameter and the Sauter mean diameter are predicted to a sufficient accuracy. However, the predicted distribution is narrower than the experimental one. Figure 7 shows the PDA velocity distribution and the CFD predictions. The range of velocity is predicted well, but the PDA measurement shows a higher frequency of velocities in the range of $10 \mathrm{~m} / \mathrm{s}$. This can be attributed to the fact that the PDA data

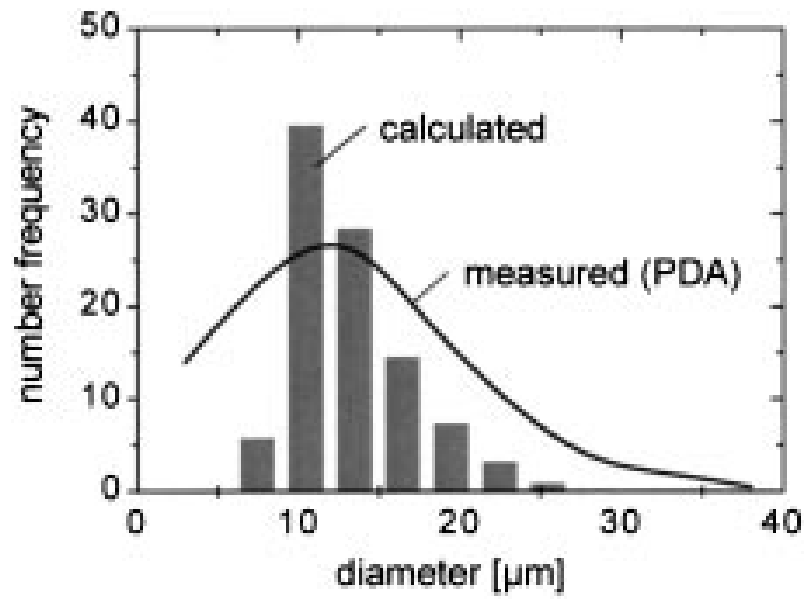

Fig. 6 CFD-predicted and PDA-measured frequency of droplet sizes, temporally and spatially averaged at a distance of $50 \mathrm{~mm}$ from the nozzle exit.

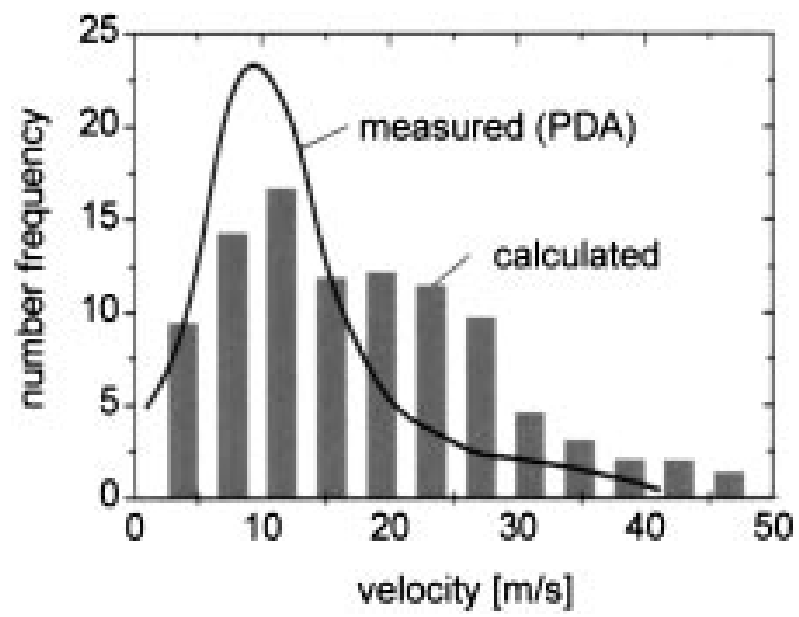

Fig. 7 CFD-predicted and PDA-measured frequency of droplet velocities, temporally and spatially averaged at a distance of $50 \mathrm{~mm}$ from the nozzle exit.

were obtained from a large number of subsequent injections and were afterwards temporally and spatially averaged. By doing so, droplets from a previous injection can be re-entrained into the measurement plane by recirculation effects, thus leading to an increase in the frequency of low velocities and small droplets. Such an effect is not modelled by CFD, where evaluation is restricted to a single injection.

\subsection{Charge motion generation}

The air guided stratified charge mode of a tumble guided DI gasoline engine requires an exact control of the charge motion to ensure that the fuel vapour cloud reaches the spark plug at spark timing. Charge motion is controlled by a CVTS, which allows controlled blocking of the lower half of the split intake port (see Fig. 1). The effect of the CVTS position is investigated by numerical simulation and its results 
are presented in Fig. 8. Figure 8a shows the flow field in the vicinity of the inlet valve with an open CVTS position. It is shown that the major part of the intake air passes through the lower half of the intake port. This leads to a symmetrical flow condition at the inlet valve, although the port shape has been designed to induce a tumble motion. With the closed CVTS position (Fig. 8b), the lower half of the intake port is blocked and the intake flow is restricted to the upper half. When leaving the separated port duct the intake flow remains attached to the upper port wall and passes through the valve at the upper port side. This intake flow field results in a strong tumble motion of the cylinder charge.

\subsection{In-cylinder spray propagation and mixture formation}

Using the validated HPSI atomization model, full simulations of the in-cylinder processes are performed. The aim is to investigate the interacting effects of tumble charge motion and spray propagation on mixture formation in the stratified mode at $2000 \mathrm{r} / \mathrm{min}$ and 2.8 bar i.m.e.p.

The results in Fig. 9 show the droplet distribution and air-fuel ratio distribution at an early injection phase, end of injection and ignition timing. In this case the injection parameters have been optimized and correspond to type E of Table 1. In Fig. 9 the spray propagation and evaporation stages can be identified. At an early injection phase, $42^{\circ}$ BTDC, the spray consists of the pre-jet, which has a rather large penetration depth. At this stage the evaporation rate is still small due to the comparatively large droplets of the pre-jet and the moderate gas temperature and pressure. With the onset of the main conical spray, finer droplets are discharged into a less restricted gas volume, which promotes evaporation. Hence at the end of injection at $34^{\circ}$ BTDC the fuel vapour cloud coincides with the main conical spray. The droplets generated by the pre-jet are located at the spray tip. In this region the fuel-air ratio $\lambda$ is significantly smaller than in the spray core.

Due to the tumbling charge motion the spray and vapour cloud is deflected towards the spark plug. It is shown in Figs $9 \mathrm{~b}$ and $\mathrm{c}$ that the pre-jet droplets spread out at the lower lateral side of the spray tip. As this location is close to the tumble centre these droplets are hardly affected by the charge motion. The main conical spray, however, is significantly deflected by the tumble motion, so that its droplets pass above the pre-jet droplets and come close to the spark plug at the time of ignition, $28^{\circ}$ BTDC. A further effect of the tumble charge motion is that it separates the vapour cloud from the spray to some extent. Hence at the time of ignition, $28^{\circ}$ BTDC, a nearly stoichiometric mixture is found at the spark plug, while the droplets have a distance of at least $4 \mathrm{~mm}$ from the spark plug. It is worth noting that in Fig. 9 the droplets are represented according to their diameter but not their mass. At the time of ignition 87 per cent of the liquid mass has been evaporated.

In order to verify the above CFD predictions a planar laser-induced fluorescence (PLIF) technique has been used to investigate the spray propagation and mixture formation in the tumble guided gasoline DI engine. For this purpose an optical access to the in-cylinder volume has been achieved by replacing the upper part of the cylinder liner by a quartz glass ring. The PLIF technique enables the distribution
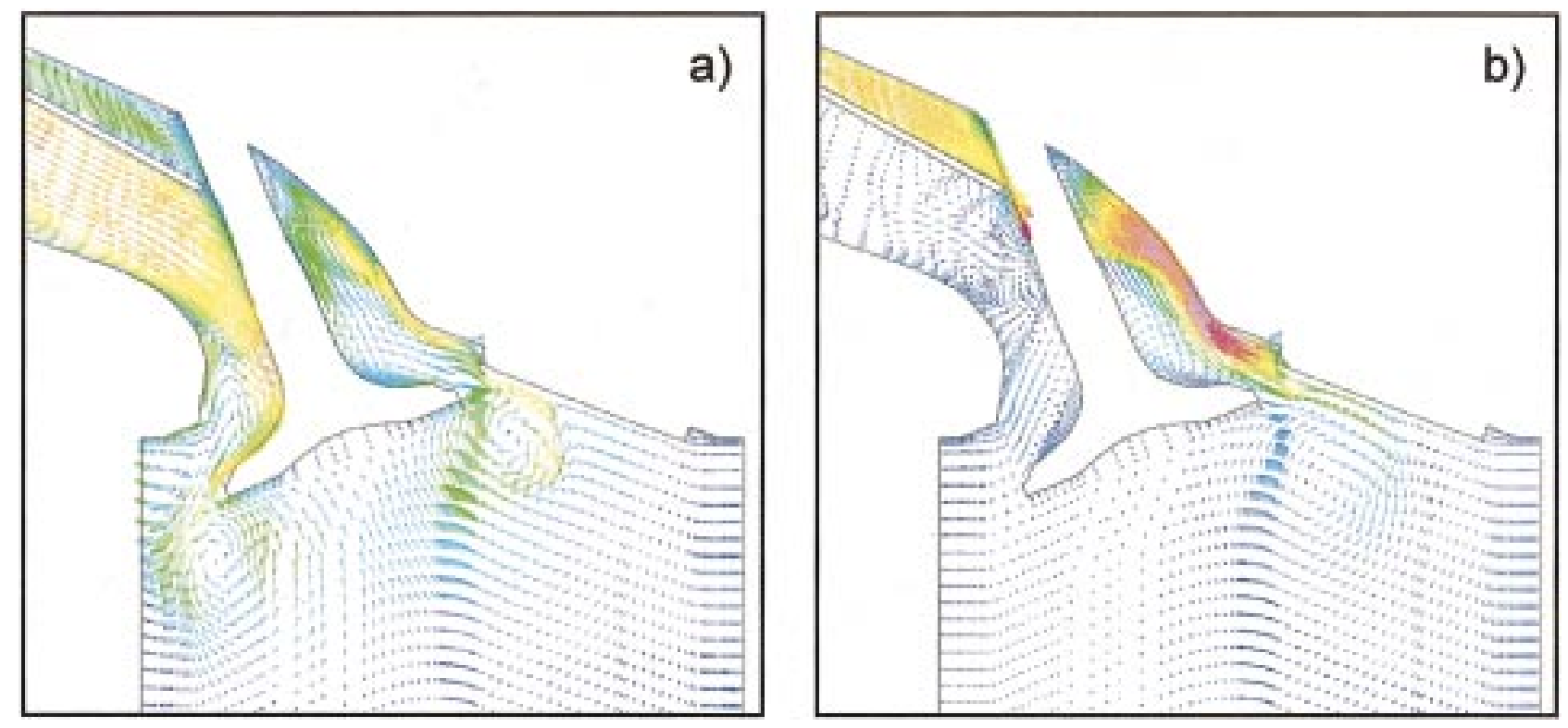

Fig. 8 Numerical prediction of the intake flow field at maximum valve lift: (a) open CVTS gate setting, (b) closed CVTS gate setting. 

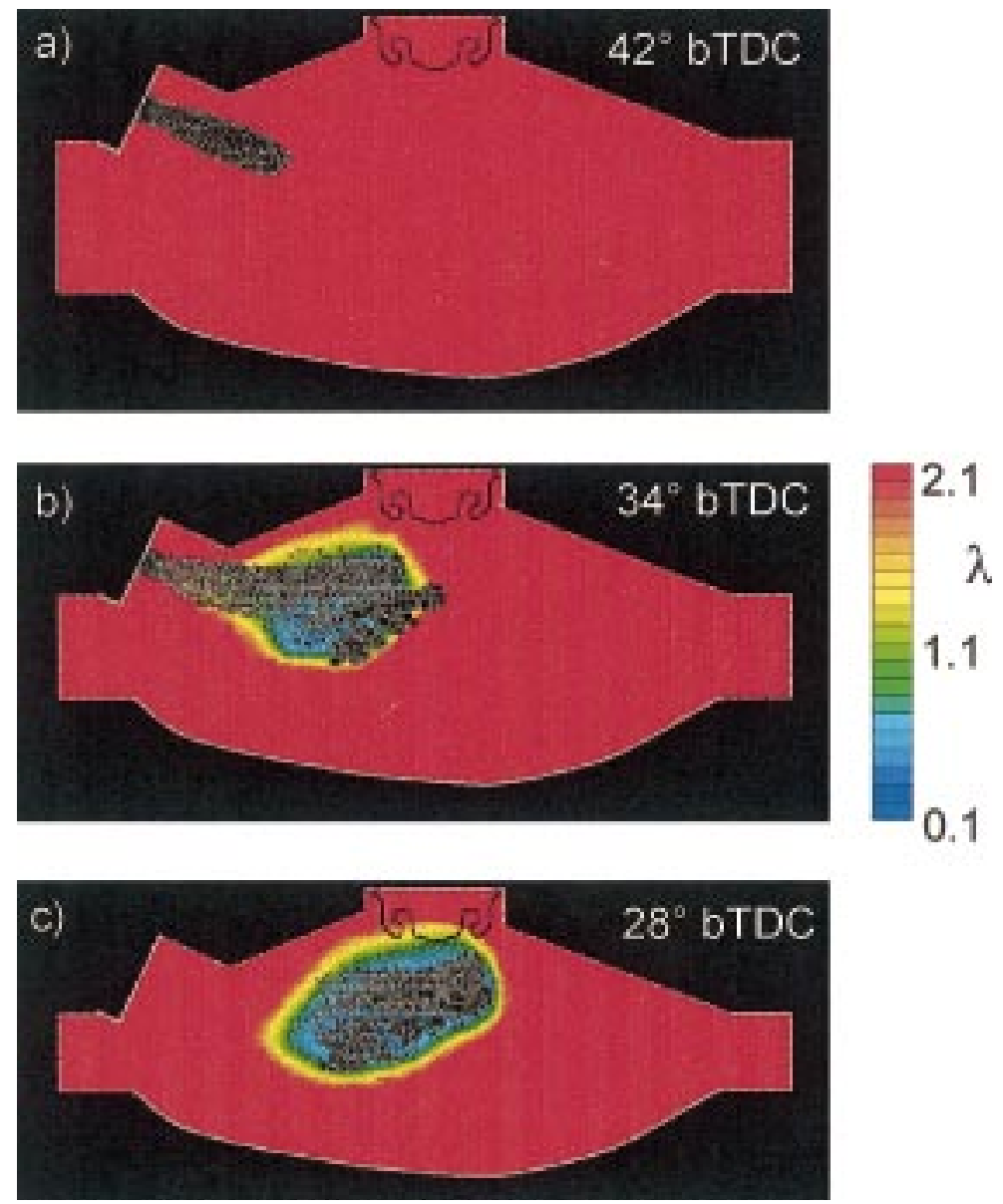

Fig. 9 Numerical prediction of the droplet and air-fuel ratio distribution in the mid-section plane of the combustion chamber: (a) early injection $\left(42^{\circ} \mathrm{BTDC}\right),(\mathrm{b})$ end of injection ( $\left.34^{\circ} \mathrm{BTDC}\right)$ and (c) time of ignition (28 BTDC).

a)
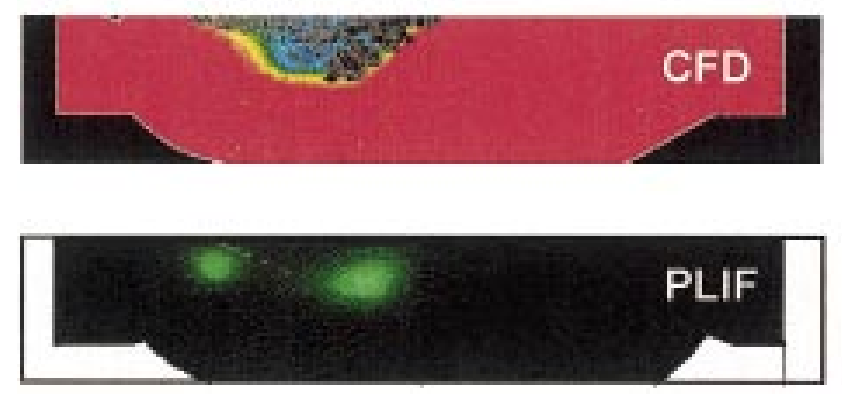

b)
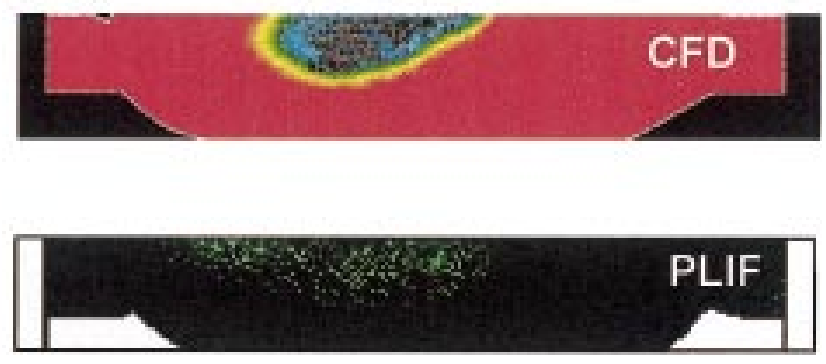

Fig. 10 Comparison of the predicted droplet and fuel vapour distribution to corresponding PLIF measurements at (a) end of injection $\left(34^{\circ}\right.$ BTDC) and $(b)$ time of ignition $\left(28^{\circ}\right.$ BTDC).

of the fuel concentration to be visualized qualitatively within a laser light sheet adjusted along the spray axis and perpendicular to the piston surface. The PLIF technique used here simultaneously detects liquid fuel fluorescence and fuel vapour fluorescence. The liquid fluorescence intensity is significantly larger than that of fuel vapour. More details on the experimental set-up can be found in reference [6].

The comparison of the fuel vapour PLIF measure- ment and the CFD predictions is shown in Fig. 10. At the end of injection, $34^{\circ}$ BTDC, the PLIF result shows two intensity maxima. These maxima can be attributed to the fuel droplets from the pre-jet and the conical main spray, as a comparison of the numerical predictions shows. The position of the area of fluorescence agrees well with the predicted position of the spray and vapour cloud. At $28^{\circ}$ BTDC the fluorescence intensity is significantly smaller since only minor traces of liquid fuel are present. The 
penetration depth of the fluorescence area agrees well with the CFD-predicted penetration depth of the fuel vapour cloud. In the region close to the injector the CFD simulation underpredicts the fuel concentration.

\section{Conclusions}

The above results show that the CFD analysis provides valuable information on the spray propagation and mixture formation in a tumble guided gasoline DI engine. In order to achieve reliable predictions, accurate models of the atomization and spray development are required. For this purpose an atomization model for high-pressure swirl injectors has been described and its results have been compared to Schlieren visualization and PDA measurements for validation. It has been shown that the approach utilized here is capable of predicting the most important effects like nozzle orifice diameter, cone angle or injection pressure on spray development.

The spray simulation also reveals the importance of the pre-jet on the overall spray behaviour. The pre-jet carries a sufficient momentum to induce a secondary recirculating gas flow, which strongly contracts the main conical spray. Additionally, the pre-jet also affects the spray penetration length. At present the temporal development of the pre-jet is described on an empirical basis. With respect to its importance for spray behaviour, there is a strong need to gain a better understanding and control of the pre-jet.
The in-cylinder CFD analysis shows that the tumble charge motion strongly affects the spray propagation and mixture formation in the stratified operation mode. It has been confirmed that the tumble charge motion largely helps to transport the fuel vapour cloud towards the spark plug. Hence it can be stated that the use of CFD simulation helps to improve understanding of the interaction between the flow field, spray propagation and evaporation. In effect this enables optimization of the flow control to be found and optimized injection parameters to be predicted for tumble guided gasoline DI engines.

\section{References}

1 El Tahry, S. H. The $k-\varepsilon$ equation for compressible reciprocating engine flows. Am. Inst. Aeronaut. Astronaut. J. Energy, 1983, 7(4), 345-353.

2 Gosman, A. D. and Ioannides, S. I. Aspects of computer simulation of liquid-fuelled combustors. Am. Inst. Aeronaut. Astronaut. J. Energy, 1983, 7(6), 482-490.

3 Han, Z., Fan, L. and Reitz, R. D. Multidimensional modelling of spray atomization and air-fuel mixing in a direct-injection spark-ignition engine. SAE Paper 970884, 1997.

4 Reitz, R. D. and Diwakar, R. Structure of high-pressure fuel spray. SAE Paper 870598, 1987.

5 Cousin, J., Ren, W. M. and Nally, S. Recent developments in simulation of internal flows in high pressure swirl injectors. Oil Gas Sci. Technol.-Rev. IFP, 1999, 54(2), 227-231.

6 Lang, O., Willems, W. and Grigo, M. Theoretical and experimental investigations on a direct injected S.I. engine. In Proceedings of the 7th Aachener Kolloqium on Fahrzeug- und Motorentechnik, 5-7 October 1998. 